\title{
Deformation behavior at rolling and tension under current in TiNi alloy
}

\author{
V. Stolyarov ${ }^{\mathrm{a}}$ \\ Mechanical Engineering Research Institute of Russian Academy of Science, \\ Maly Kharitonievsky lane, 4, 101990, Moscow
}

\begin{abstract}
The paper presents data on pulse current effects on deformability, strength and ductility of shape memory TiNi alloy, processed by electroplastic rolling (EPR). It was found that deformability and elongation to failure can be enhanced by electropulse current. It has considered deformation behavior of the TiNi alloy both at EPR processing and tension with pulse current. It is shown that EPR increases significantly strain to failure and refines microstructure to grain size less $100 \mathrm{~nm}$. Stresses jumps up and down were observed on the stress-strain curves at tension with current. Different direction of stress jumps is conditioned by martensite transformation and electroplastic effect, correspondingly.
\end{abstract}

\section{Introduction}

Recently for increase of plasticity submicrocrystalline (SMC) and nanocrystalline (NC) materials the ways based on structure design are offered [1-3]. Other approach that also can be considered as a method of technological plasticity increase is use of electropulse treatment (EPT) and electroplastic deformation (EPD) [4, 5]. For example, essential elongation increase without decrease in strength after EPT of brittle magnesium AZ61 alloy is demonstrated in [5], and opportunities of electroplastic effect application are shown in [4].

Special place among new materials belongs to shape memory TiNi-based alloys. In coarse-crystalline (CC) and microcrystalline (MC) states they possess enough high plasticity (40-60\%), one of which reasons is thermoelastic martensitic transformation caused by temperature, stress or strain change [6]. Nanostructuring such alloys raises not only strength properties but also functional ones - recovery stress and maximum completely recoverable strain [7]. Earlier it has been shown, that EPD is one of severe plastic deformation technique to process nanostructure in TiNi alloys [8]. Therefore, it would be important to know, how deformability and plasticity of EPD TiNi alloy change. The paper is devoted to studying of pulse current influence on deformability and plasticity of shape memory TiNi alloy processed by EPD.

\section{Experimental procedure and materials}

The initial $\mathrm{Ti}_{49.4} \mathrm{Ni}_{50.6}$ and $\mathrm{Ti}_{49.3} \mathrm{Ni}_{50.7}$ alloys with very close compositions have been subjected to quenching from $800{ }^{\circ} \mathrm{C}$ in cold water to obtain $\mathrm{CC}$ structure with the mean grain size of $50 \mu \mathrm{m}$. Then there were used the following techniques and technological combinations to process SMC and $\mathrm{NC}$ states: 1 - equal channel angular pressing at $450{ }^{\circ} \mathrm{C}$ with eight passes (ECAP $450{ }^{\circ} \mathrm{C}(8)$ ); 2 - high pressure torsion at 5 revolution (HPT (5)); 3 - multiple electroplastic rolling (EPR) of CC alloy and 4 - EPR of SMC alloy on strips with cross section $2 \times 6$ mm $^{2}$ under pulse unipolar current with current density $\mathrm{j}=84-222 \mathrm{~A} / \mathrm{mm}^{2}$, pulse duration $(8-10) \times 10^{-3} \mathrm{c}^{-1}$ and frequency $10^{3}$ $\mathrm{Hz}$; the details of the method are described in [8]. After each pass the sample was cooled to water to avoid significant heat effect. The deformability of the EPR samples was estimated by true strain $e=\ln t_{i} / t_{f}\left(t_{i}, t_{f}-i n i t i a l\right.$ and final strip thickness) that was varying in the interval of e $=0.5-2.0$. The microstructure was investigated by TEM on specimens with annealing temperatures (Tan) of 450 and $550{ }^{\circ} \mathrm{C}$ that respond to recrystallization and aging structure changes. Mechanical properties were studied during tension at room temperature and strain rate $0.5 \mathrm{~mm} / \mathrm{min}\left(0.4 \times 10^{-3} \mathrm{c}^{-}\right.$ ${ }^{1}$ ) on MTS device (without current) and horizontal IM-5081 machine (with single and multiple pulses current). To clarify current possibility for structure relaxation EPT during $5 \mathrm{~s}$ at $\mathrm{j}=110 \mathrm{~A} / \mathrm{mm}^{2}$ has been used instead of furnace annealing for one experiment.

a e-mail: vlstol@mail.ru

This is an Open Access article distributed under the terms of the Creative Commons Attribution-Noncommercial License (http://creativecommons.org/licenses/by-nc/3.0/), which permits unrestricted use, distribution, and reproduction in any noncommercial medium, provided the original work is properly cited. 


\section{Experimental data}

\subsection{Microstructure}

The results of TEM investigation of severe plastic deformed alloys processed by ECAP, EPR $\left(e=1.81, \mathrm{j}=168 \mathrm{~A} / \mathrm{mm}^{2}\right)$, ECAP + EPR $\left(e=1.91, j=200 \mathrm{~A} / \mathrm{mm}^{2}\right)$ and a subsequent post-deformation annealing have revealed formation of SMC or NC structures of the austenite B2 phase with a mean grain size of 600, 100 and $50 \mathrm{~nm}$, correspondingly (Fig.1). Detailed analysis of diffraction pictures for EPR and ECAP + EPR samples before annealing testifies to the presence amorphous and B19' phases in a small fraction and a crystallographic texture (200).

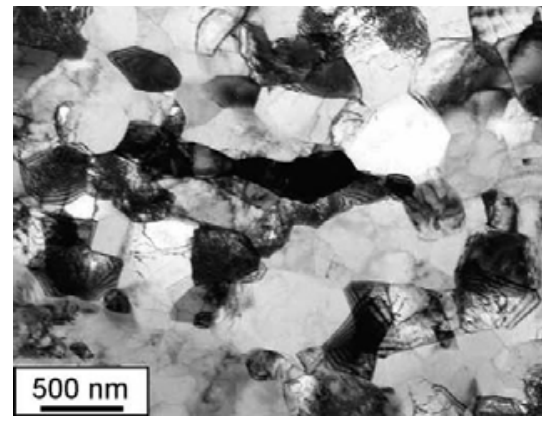

a) $\operatorname{Tan}=550{ }^{\circ} \mathrm{C}-1 \mathrm{~h}$

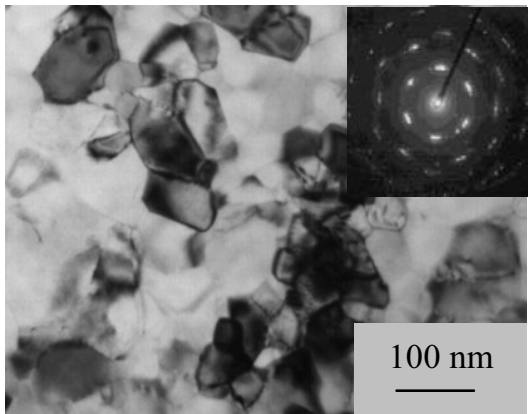

b) $\operatorname{Tan}=450{ }^{\circ} \mathrm{C}-1 \mathrm{~h}$

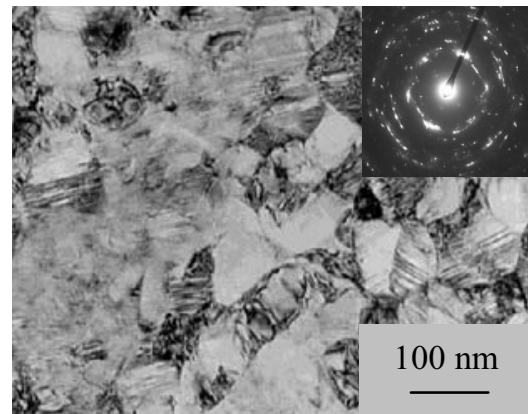

c) $\operatorname{Tan}=450^{\circ} \mathrm{C}-1 \mathrm{~h}$

Fig. 1. Bright fields TEM micrographs of $\mathrm{Ti}_{49.4} \mathrm{Ni}_{50.6}$ alloy processed by ECAP (a), EPR (b) and ECAP + EPR (c) and the following annealing.

Other structure feature of these pictures consists of different intragranular defect structure. There is a high dislocation density within the grains and on the grain boundaries of ECAP sample (Fig. 1a) whereas EPR sample grains have no practically lattice defects (Fig.1b). On the contrary the grains of ECAP + EPR sample have many thin microtwins of B19'-phase (Fig.1c). Thus the processed states differ not only in grain size but also in phase composition and defect density. Note that EPR technique transformed CC and SMC structures to NC structures with close grain size.

\subsection{Deformability}

Deformability of the alloy at cold rolling with current is considerably higher than without current (table 1). Deformability increases with pulse current density for CC and SMC alloys. The maximum strain to fracture for CC and SMC alloys cold rolled with current $(\mathrm{e}=1.81-1.91)$ was three times above than for the same alloys cold rolled without current $(\mathrm{e}=0.54-0.59)$. Effect of EPR depends on structure state and starts at current density more than 60 and 100 $\mathrm{A} / \mathrm{mm}^{2}$ for $\mathrm{CC}$ and SMC states, correspondingly.

Table 1. Deformability of alloys at cold rolling without and with a current

\begin{tabular}{|c|c|c|c|c|}
\hline Treatment & $\begin{array}{c}\text { initial } \\
\text { state }\end{array}$ & $\begin{array}{c}\text { Current density, } \\
\mathrm{j} \\
{\left[\mathrm{A} / \mathrm{mm}^{2}\right]}\end{array}$ & Fracture strain, e & Fracture observation \\
\hline \multirow{3}{*}{ Quenching } & \multirow{3}{*}{$\mathrm{CC}$} & 0 & 0.54 & By separation \\
\cline { 3 - 5 } & & 60 & 0.55 & By separation \\
\cline { 3 - 5 } & & 84 & 0.84 & By single microcracks \\
\cline { 3 - 5 } & \multirow{3}{*}{ ECAP } & 168 & 1.81 & by separation \\
\cline { 3 - 5 } & \multirow{3}{*}{ SMC } & 0 & 0.59 & by single microcracks \\
\cline { 3 - 5 } & & 100 & 0.59 & no \\
\cline { 3 - 5 } & & 200 & 1.20 & 1.91 \\
\cline { 3 - 5 }
\end{tabular}

Fracture type at a cold rolling depends on a mode of a current also. For the lack of a current fracture type is brittle with sample separation into parts (Fig.2a). At current density more than $60 \mathrm{~A} / \mathrm{mm} 2$ brittle fracture has not observed. In this case cold rolling accompanied by edge microcracks (Fig.2b) which disappear with increase in current density more than $100 \mathrm{~A} / \mathrm{mm}^{2}$. 


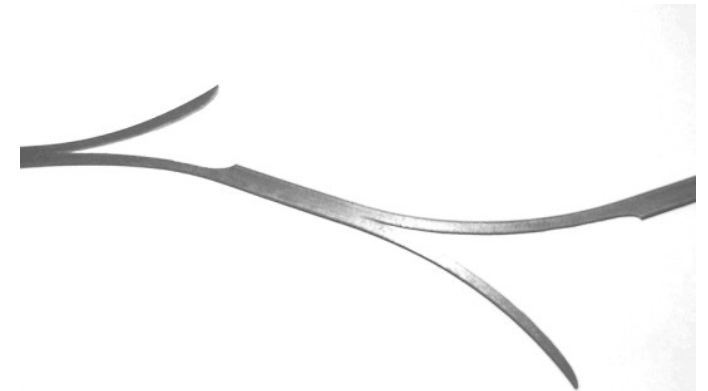

a)

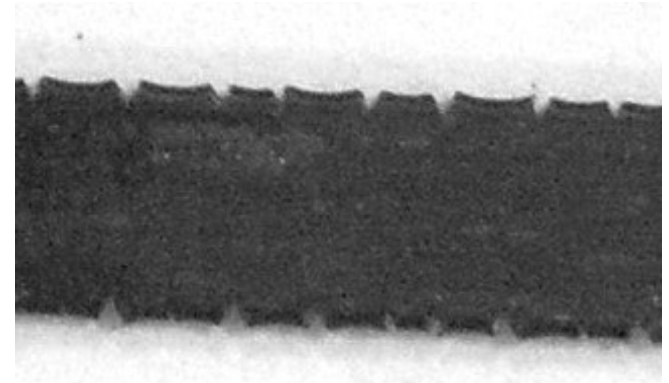

b)

Fig. 2. Sample view after cold rolling without (a) and with (b) current

\subsection{Mechanical behavior and properties}

\subsubsection{Tension without current}

The mechanical behavior of shape memory TiNi alloys differs from those for traditional materials. The view of stressstrain curves depends on a relation of strain temperature Ts (Ts $=\mathrm{RT}$ in our case) and start and finish transformation temperatures at cooling $\left(\mathrm{M}_{\mathrm{s}}, \mathrm{M}_{\mathrm{f}}\right)$ or heating $\left(\mathrm{A}_{\mathrm{s}}, \mathrm{A}_{\mathrm{f}}\right)$. For the $\mathrm{Ti}_{49.3} \mathrm{Ni}_{50.7}$ alloy in the quenched and EPR states this relation corresponds $M_{s}<T_{s}<A_{f}$ and typical room temperature tensile stress-strain curve is shown in Fig. 3a. It is seen there is a yield stress plateau corresponding to reverse phase transformation $\mathrm{A} \leftrightarrow \mathrm{M}$. Beyond a plateau irreversible elastic-plastic martensite deformation is observed. Application EPR processing leads to strong hardening and disappearance of a transformation plateau (Fig.3b). The subsequent annealing at $450{ }^{\circ} \mathrm{C}$ resulted to recovery of the stress plateau at higher stress and to occurrence of an additional plateau at small stress (Fig.3c).

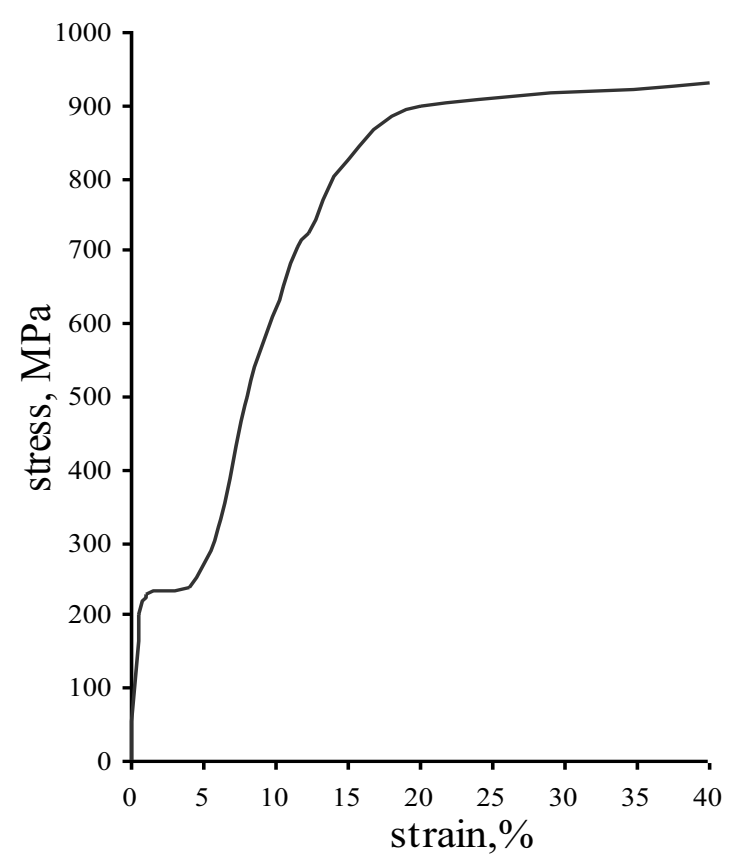

a)

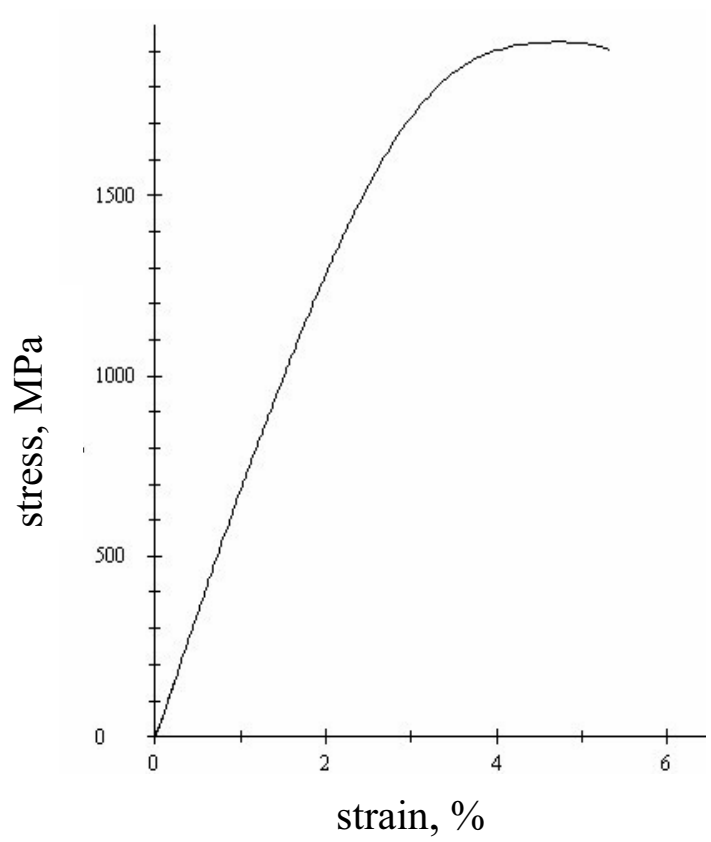

b) 


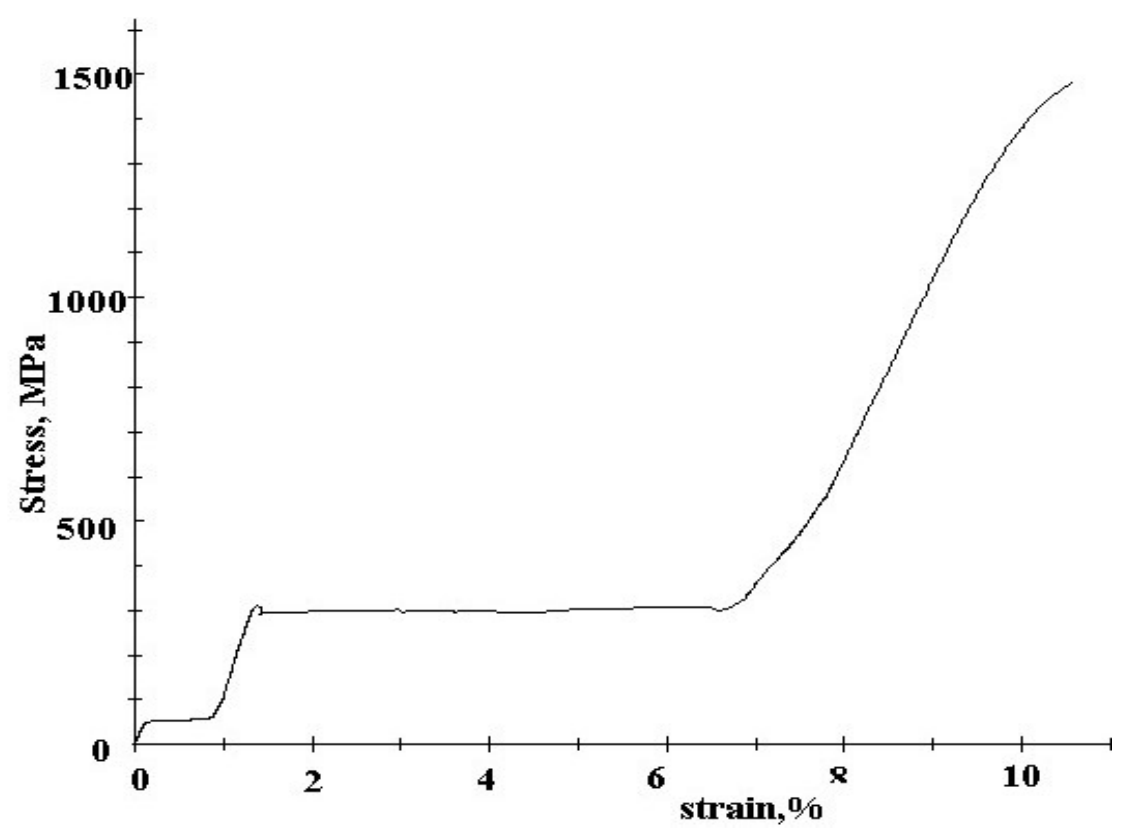

c)

Fig. 3. Stress-strain curves for $\mathrm{Ti}_{49,3} \mathrm{Ni}_{50,7}$ alloy in $\mathrm{CC}$ (a) and и $\mathrm{NC} \mathrm{(b,} \mathrm{c)} \mathrm{states} \mathrm{before} \mathrm{(b)} \mathrm{and} \mathrm{after} \mathrm{(c)} \mathrm{annealing.}$

Mechanical properties for the alloy subjected to EPR and the following annealing are presented in the table 2 . For comparison, data for quenched state, ECAP [9, 10] and HPT techniques after annealing are given, as well. These data demonstrate that the TiNi alloy in NC state processed by EPR and a subsequent annealing has higher US, YS that in CC and SMC states. It's seen that strength increases but elongation to failure decreases with grain refinement that is typically for the most materials. Highest strength and smallest elongation to failure correspond to NC state with very small grain size. Ductility has been significantly improved by post-deformation annealing at 200,450 and $550{ }^{\circ} \mathrm{C}$. Note that $\varepsilon_{\mathrm{m}}$ for $\mathrm{NC}(8.1 \%)$ state is two times higher that for CC $(4.0 \%)$ and SMC states $(3.5 \%)$.

In table 2 mechanical properties of EPR alloy subjected to electropulse treatment (EPT) during $5 \mathrm{~s}$ at $\mathrm{j}=110$ $\mathrm{A} / \mathrm{mm}^{2}$ instead of post-deformation annealing at $450{ }^{\circ} \mathrm{C}-1$ hour are given. Comparison of mechanical properties of EPR alloy after both kinds of processing shows advantage of EPT both in strength and plasticity.

Table 2. Mechanical properties at tension of $\mathrm{Ti}_{49.3} \mathrm{Ni}_{50.7}$ alloy

\begin{tabular}{|l|l|l|l|l|l|l|l|}
\hline Treatment & State & $\begin{array}{c}\text { grain } \\
\text { size, } \\
{[\mu \mathrm{m}]}\end{array}$ & $\begin{array}{c}\varepsilon_{\mathrm{m}} \\
{[\%]}\end{array}$ & $\begin{array}{c}\sigma_{\mathrm{M}}, \\
{[\mathrm{MPa}]}\end{array}$ & $\begin{array}{c}\text { YS } \\
{[\mathrm{MPa}]}\end{array}$ & $\begin{array}{c}\text { UTS, } \\
{[\mathrm{MPa}]}\end{array}$ \\
$\begin{array}{l}\delta \% \\
{[\%]}\end{array}$ \\
\hline Quenching from $800^{\circ} \mathrm{C}$ & $\mathrm{CC}$ & 50 & 4 & 210 & 600 & 940 & 40 \\
\hline ECAP $450^{\circ} \mathrm{C}(8)+550^{\circ} \mathrm{C}$ & $\mathrm{SMC}$ & 0.6 & 4.5 & 230 & 860 & 1150 & 25 \\
\hline ECAP $450^{\circ} \mathrm{C}(8)$ & $\mathrm{SMC}$ & 0.3 & 3.5 & 290 & 1140 & 1240 & 15 \\
\hline EPR $(\mathrm{e}=1.81)$ & $\mathrm{NC}+\mathrm{A}$ & 0.08 & - & - & 1587 & 1926 & 2.4 \\
EPR $(\mathrm{e}=1.81)+450^{\circ} \mathrm{C}$ & $\mathrm{NC}$ & 0.10 & 8.1 & 250 & 1200 & 1300 & 9.6 \\
EPR $(\mathrm{e}=1.81)+\mathrm{EPT}\left(5 \mathrm{~s}, \mathrm{j}=110 \mathrm{~A} / \mathrm{mm}^{2}\right)$ & $\mathrm{NC}$ & 0.10 & & 500 & 1350 & 1550 & 10.5 \\
ECAP $+\mathrm{EPR}(\mathrm{e}=1.91)+450^{\circ} \mathrm{C}$ & $\mathrm{NC}$ & 0.05 & 5 & 294 & 1395 & 1481 & 8.0 \\
\hline $\mathrm{HPT}(5)+200^{\circ} \mathrm{C}$ & $\mathrm{NC}$ & 0.02 & - & 320 & 1570 & 2650 & $<1$ \\
\hline
\end{tabular}

$\varepsilon_{\mathrm{m}}$ and $\sigma_{\mathrm{m}}-$ martensitic-induced transformation strain and stress

\subsubsection{Tension with pulse current}

The mechanical behavior at tension under single pulses current for the alloy after quenching, EPR $(\mathrm{e}=1.91, \mathrm{j}=$ $200 \mathrm{~A} / \mathrm{mm}^{2}, \tau=160 \mu \mathrm{s}$,) and EPR $+450{ }^{\circ} \mathrm{C}$ is shown on Fig.4. Distinctive feature of stress-strain curves under pulse 
current is occurrence of stress jumps, each of which corresponds to a single current pulse. Jump direction (up or down) and jump amplitude (25-300 MPa) depend both on alloy structure state and pulse current mode.

Stress jumps to down amplitude less $50 \mathrm{MPa}$ have been observed only in quenched CC alloy. They are placed beyond of stress plateau $\sigma_{\mathrm{m}}$ after a yield stress point for martensite. Amplitude of stress jump increases slightly with strain (Fig.4a).

Stress jumps to up have been observed at $\sigma \geq \sigma_{\mathrm{m}}$ for $\mathrm{CC}$ and NC states. Maximal stress jump amplitude of $200 \mathrm{MPa}$ corresponds to quenched alloy (Fig.4a). The stress jump amplitude decreases with strain from maximal to zero at $\mathrm{j}=$ $2 \times 10^{3} \mathrm{~A} / \mathrm{mm}^{2}$ and $\tau=1 \mu \mathrm{s}$ (Fig.4a). Decrease in duration from 1 to $0.1 \mu \mathrm{s}$ (Fig. $4 \mathrm{~b}$ ) and density of a single current pulse from 5.3 to $3.0 \times 10^{3} \mathrm{~A} / \mathrm{mm}^{2}$ (Fig.4c) causes decrease in stress jump amplitude up to its disappearance. On the contrary, transition from single pulse current to multiple pulses current sharply raises stress jump amplitude up to $500 \mathrm{MPa}$ (Fig.4d).

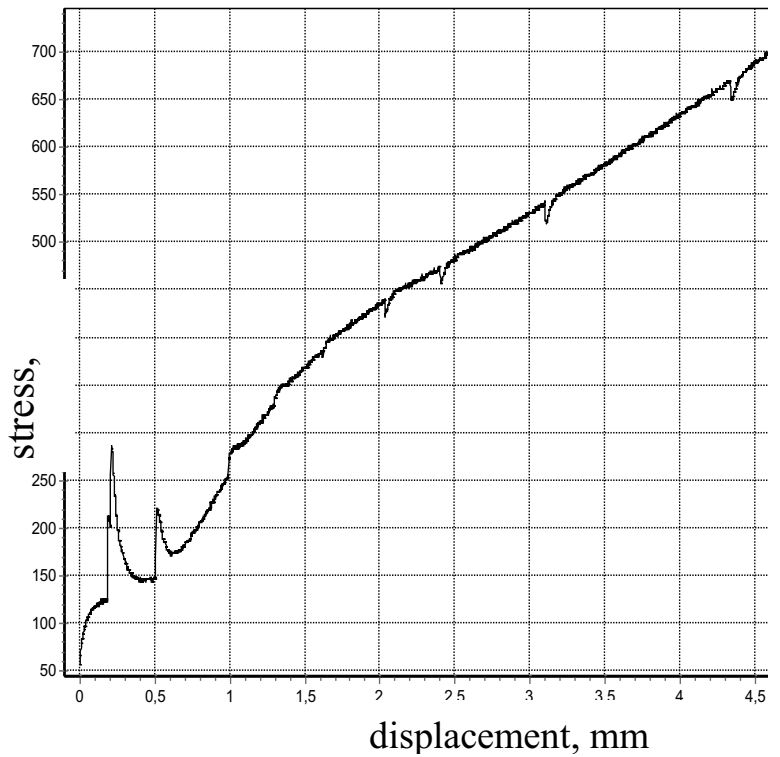

a)

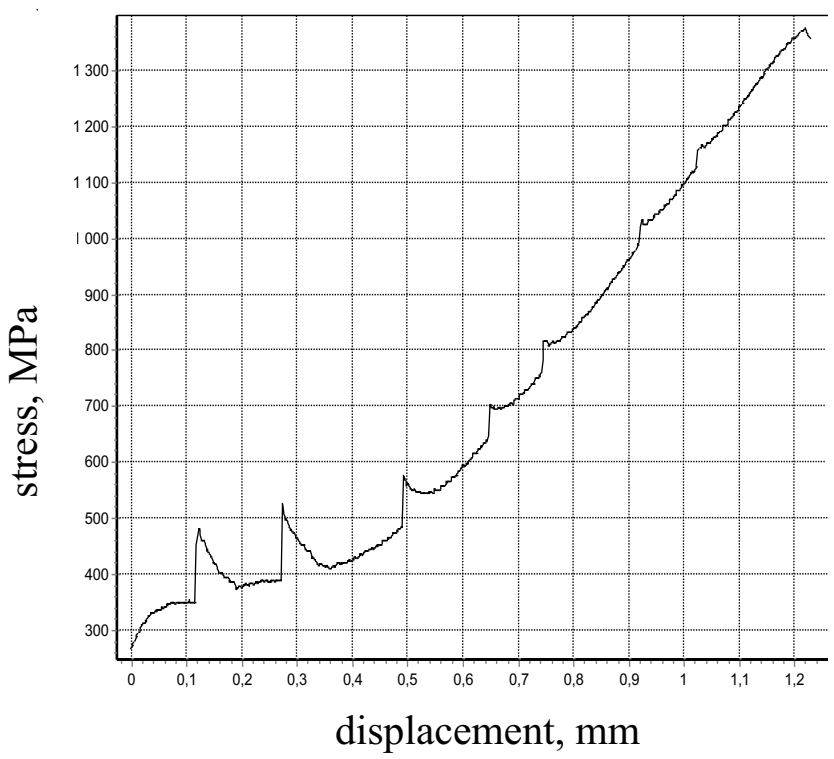

c)

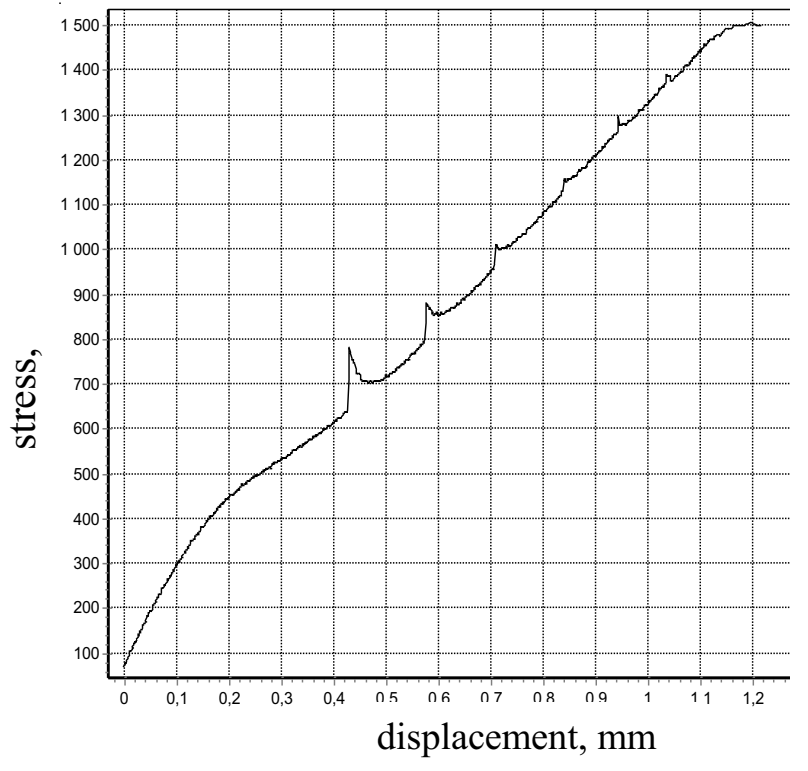

b)

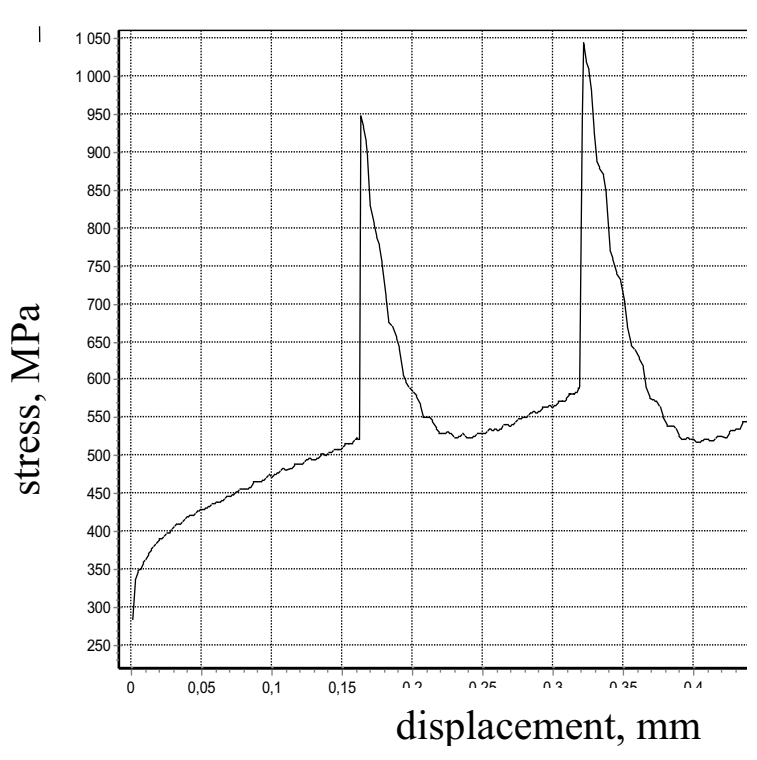

d)

Fig. 4. Typical stress-strain curves at tension with single (a, b, c) pulse and multi-pulse (d) current for TiNi alloy in CG (a), EPR states before (b) and after annealing at $450{ }^{\circ} \mathrm{C}(\mathrm{c}, \mathrm{d})$.

Comparison Fig.3b and Fig.4b demonstrate that an inflexion point (degeneration of plateau), corresponding transformation, is appeared under action of a current in NC state before annealing.

In table 3 mechanical properties at tension with current of CC and NC alloy are shown. Here, as well as at tension without a current grain refinement leads to increase of strength and decrease in plasticity. Post-deformation annealing promotes partial restoration of elongation to failure. It has also appeared that the pulse current influences on 
shape of stress-strain curves and plasticity. Comparison of elongations to failure for CC and NC states in table 2 and 3 show that their values at tension with a current in 1.5-2 times higher than without current.

Table 3. Mechanical properties of $\mathrm{Ti}_{49.3} \mathrm{Ni}_{50.7}$ alloy at tension with current.

\begin{tabular}{|l|l|l|c|c|c|c|}
\hline Treatment & \multirow{2}{*}{ State } & $\begin{array}{l}\text { grain } \\
\text { size, } \\
{[\mu \mathrm{m}]}\end{array}$ & $\sigma_{\mathrm{m}},[\mathrm{MPa}]$ & $\begin{array}{c}\text { YS, } \\
{[\mathrm{MPa}]}\end{array}$ & $\begin{array}{c}\text { UTS, } \\
{[\mathrm{MPa}]}\end{array}$ & $\begin{array}{c}\delta, \\
{[\%]}\end{array}$ \\
\cline { 1 - 5 } & $\mathrm{CC}$ & 50 & $150 / 210$ & $400 / 600$ & $750 / 940$ & $60-80 / 40$ \\
\hline EPR $(\mathrm{e}=1.81)$ & \multirow{2}{*}{$\mathrm{NC}$} & 0.08 & $450 /-$ & $1480 / 1587$ & $1500 / 1926$ & $5 / 2.4$ \\
\cline { 1 - 6 } & & 0.10 & $400 / 250$ & $1170 / 1200$ & $1300 / 1300$ & $17 / 9.6$ \\
\hline
\end{tabular}

Numerator/denominator is value for tension with/without current

\section{Discussion}

As a result of deformation techniques varying the microstructures, differing by a grain size, type of intragranular defects, phase composition and crystallographic texture (Fig.1) have been received in TiNi alloy. Each of the mentioned structural features is capable to influence on alloy plasticity, raising or lowering it. For example, it has been found out absence of microtwins in a microstructure quenched CC alloy subjected EPR (Fig.1b). It can be potential for plasticity increase. The important result is fact that possible grain growth and degradation SMC structure has not observed at electroplastic rolling of ECAP alloy. Moreover, electroplastic rolling promotes nanostructure formation with plenty of microtwins (Fig.1c).

As follows from the table 1 strongest influence of a pulse current on alloy deformability has been revealed. Introduction of a pulse current in deformation zone at a cold rolling of low conducting intermetallic TiNi alloy raises deformability two-three times in comparison with cold rolling without current (table 1). Experimental data show that deformability with current raises not only for CC but for SMC state also [11]. Besides the raised deformability arises only after application of critical current density $j_{c r}=84$ and $160 \mathrm{~A} / \mathrm{mm}^{2}$, accordingly. It is clear because the enhanced deformability has not observed below these meanings. Critical value $\mathrm{j}_{\text {cr }}$ for CC TiNi is twice higher than the critical current density for commercial pure coarse-grained titanium in [12]. Considering the low electroconductivity of an intermetallic TiNi alloy, these results can be considered as comparable. Difference between crucial current density for $\mathrm{CC}$ and SMC is conditioned by their various initial ductility (Table 2). Presence of critical current density can be considered as argument for nonthermal nature of effect. It is also confirmed by direct temperature measurements by the infra-red chamber. I t has been shown the greatest possible temperature on the sample surface after multiple rolling does not exceed $150^{\circ} \mathrm{C}$. Taking into account short duration (high-velocity) process and immediate water cooling of the sample after each pass it is possible to neglect by the total thermal heating. Nevertheless, high local heating in places of a microdefects cluster is possible. It is necessary to emphasize that before electro stimulation of plastic deformation (electroplastic effect) observed at tension of monocrystals of pure metals or polycrystalline alloys without phase transformations with good conductivity $[4,12]$.

For TiNi alloy strong deformation hardening is typical. That is why it assists to brittle fracture at absence of relaxation processes in structure and large strain (Fig.2a). Introduction of pulse current, apparently, leads to interaction of electronic "wind" with pile-up of dislocation and a structural relaxation that promotes the raised deformability. The main reason of the appearance of microcracks during EPR is connected with a stress-strain state that changes from bulk triaxial to flat biaxial at thickness reduction of the sample (Fig.2b). Experiments have also shown that removal of edge microcracks during EPR allows enhancing strain to failure.

Shape features of stress-strain curves at tension of TiNi alloy is caused by phase transformation (Fig.3). Presence stress plateau at 210 and $294 \mathrm{MPa}$ serves the evidence of induced B2 $\rightarrow$ B19 transformation (Figs.3.a,c) The plateau near $50 \mathrm{MPa}$ for NC state (Fig.3c) can be connected with reorientation or reverse transformation of B19 phase [13]. Absence of any plateau on Fig. $3 \mathrm{~b}$ is connected with stabilization of martensite phases by EPR which can turn in austenite only at heating above $250^{\circ} \mathrm{C}$ [14]. The general for all curves is absence of a necking stage. The high uniform elongation for CC state (Fig.3a) sharply contrasts with its absence in NC state before and after annealing (Figs.3b, c). Note that the total length of a plateau $\left(\varepsilon_{\mathrm{m}}\right)$ for NC annealed state is maximal and in two times more than in CC state. It testifies to greater induced transformation ductility.

Data in table 2 show that structure refinement of alloy TiNi by deformation methods leads to sharp reduction of plasticity. Decrease of grain size from tens micron up to tens nanometers reduces elongation to failure more than by the order. But, the post-deformation annealing promotes partial restoration of plasticity. Observable changes of plasticity in TiNi alloy with reverse phase transformation do not differ from mechanical behavior of metals and alloys without phase transformation $[15,16]$. It testifies to a generality of deformation mechanisms in nature different alloys. Note that decrease and increase of plasticity of TiNi alloy is connected not only with change of the grain size but also with structure-phase transformations - partial amorphization due to severe plastic deformation and nanocrystallization at heating [8]. 
For lack of publications on EPE in nanomaterials opportunity of the effect display in nanostructure nitinol was not clear. Though below data about EPE and their possible connection with increase of technological deformability in nitinol will be discussed for the first time this question remains opened and needs detailed researches in the future.

The nature of stress jumps on stress-strain curves at a tension with a current is various and reflects preferential display either phase transformations or electroplastic effect. Stress jumps up are connected with reverse transformation M A which is stimulated with a current pulse and easy rise in temperature. The nature of such jumps is similar to display of a reversible stress at the sample loading by tension. As martensite in different quantities is present at all structure states during tension also stress jumps up are on all tension curves. The jump amplitude dependence on current density (Fig.4a), pulse duration (Fig.46) and pulse number (Fig.4d) is clear because of increase of the parameters leads to rise in sample temperature and accordingly, to volume of the transformed phase.

Stress jumps down in comparison with stress jumps up have noticeably smaller amplitude and, apparently, reflect display of EPE. In a stable state both martensite and austenite phases are capable structurally to relax under action of a current. Thus EPE is observed only for CC state. Probably, for release of dislocation clusters and display EPE in NC state higher current parameters are required.

Note the important circumstance. Both kinds of stress jumps stimulate the raised plasticity, as connected with the induced phase transformation, and with usual dislocation mobility. It is visible in increase in length stress-plateau, occurrence of inflexion point and uniform elongation stage.

The pulse current has positive influence on ductility not only in combination with cold rolling or tension but also when it operates independently during EPT as source of Joule heating (Table 3). Efficiency of EPT processing consists in repeated decrease in operational time and in achievement of the best combination of strength and ductility, in comparison with traditional annealing. It is possible to assume that direct heating by a pulse current selectively influences on dislocation clusters and helps to form homogeneous structure.

\section{Summary}

Combination electroplastic rolling and post-deformation annealing in coarse-crystalline nickel enriched TiNi alloys allows generating homogeneous nanostructure without deformation defects like microtwins and dislocations.

Electroplastic rolling increases deformability of $\mathrm{Ti}_{49.3} \mathrm{Ni}_{50.7}$ alloy in 1.5-3 times in course-crystalline and submicrocrystalline states.

Introduction of a pulse current during tension promotes increase phase and dislocation plasticity. It has observed two different stress jumps during tension - jump up and jump down corresponding to phase transformation and electroplastic effect, correspondingly.

Electropulse treatment instead of traditional annealing can improve ductility without significant strength loss.

This work was supported by the Russian Foundation for Basic Research, grants \# \# 08-08-00497-a, 08-08-90403-Ukr_a, 08-0892202-China_a and Russian Federation Agency on Education, project 2.1.2./385.

\section{References}

[1] Y. Wang, M. Chen, F. Zhou and E. Ma: Nature, Vol. 419, p.912 (2002).

[2] C. Koch: Scripta Mater., Vol. 49, p.657 (2003).

[3] R. Valiev: Nature, Vol. 419, p.887 (2002).

[4] O. Troitski, Yu. Baranov, Yu. Avraamov, A. Shlyapin, Physical Fundamentals and Technologies of Treatment of Modern Materials (Moscow-Izhevsk, Russia, 2004).

[5] Y. Jiang, G. Tang, L. Guan, S. Wang, Z. Xu, C. Shek, Y. Zhu, J. Mater. Res., Vol. 23, 10, p.2685 (2008).

[6] V. Brailovski, S. Prokoshkin, P. Terriault, F. Trochu (Eds) Shape Memory Alloys: Fundamentals, Modeling and Applications (Quebec, Montreal, Canada, 2003).

[7] I. Khmelevskaya, S. Prokoshkin, I. Trubitsyna, M. Belousov, S. Dobatkin, E. Tatyanin, A. Korotitskiy, V.

Brailovski, V. Stolyarov, E. Prokofiev, Mater. Sci. Eng. A, Vol. 481-482, p.119 (2008).

[8] V. Stolyarov, U. Ugurchiev, I. Trubitsyna, S. Prokoshkin, E. Prokofiev, J. of High Pressure Physics and Technique, Vol.4, 16, p. 64 (2006).

[9] V. Pushin, V. Stolyarov, R. Valiev, T. Lowe and Y. Zhu, Mater. Sci. Eng. A, Vol. 410-411, p.386 (2005).

[10] V. Stolyarov, E. Prokofiev, S. Prokoshkin, S. Dobatkin, I. Trubitsyna, I. Khmelevskaya, V. Pushin and R. Valiev: Phys. Met. Metallogr., Vol.100, 6, p.91(2005).

[11] V. Stolyarov: Nanostructured Shape Memory TiNi Alloy Processed by Severe Electroplastic Deformation, Trans Tech Publications, Switzerland Materials Science Forum Vols. 584-586, p. 507 (2008).

[12] H. Conrad, Mater. Sci. Eng. A, Vol. 287, p.276 (2000).

[13] V. Stolyarov, Mater. Sci. Eng. A, Vol. 503, Issues 1-2, 15, p.18 (2009).

[14] I. Trubitsyna, S. Prokoshkin, A. Korotitsky, K. Inaekyan, V. Stolyarov, S. Makushev, I. Khmelevskaya, A.

Chirkova, A. Bugaev, D. Levin, U. Ugurchiev, J. of Functional Mater., in Russian, Vol.1, 2, p.66 (2007).

[15] H. Gleiter, Acta Mater., Vol. 48, 1, p.1 (2000).

[16] R. Valiev, R. Islamgaliev and I. Alexandrov, Progr. Mater. Sci., Vol.45 (2), p. 103 (2000). 